\title{
Relationship Between Stressful Life Events And Anxiety During The Period Of Adolescence
}

\author{
Gordana Stankovska, PhD \\ State University of Tetovo, Faculty of Philosophy, \\ Department of Psychology, Tetovo, Republic of Macedonia \\ Fadbi Osmani, PhD \\ Svetlana Pandilovska Grncarovska, PhD \\ State University of Tetovo, Faculty of Philosophy, \\ Department of Pedagogy, Tetovo, Republic of Macedonia \\ Slagana Angelkoska, MA \\ Center for Social Work, Gostivar, Republic of Macedonia
}

doi: 10.19044/esj.2016.v12n11p332 URL:http://dx.doi.org/10.19044/esj.2016.v12n11p332

\begin{abstract}
The purpose of this study is to investigate the relationships between stressful life events and anxiety during the period of adolescence. It is known that stressful life events are commonly studied risk and environmental factors in the development of psychopathology in childhood and adolescence. In addition, physical and psychological symptoms of anxiety are often associated with stressful life events. These events are related to the different experiences of conflict and disrupted communication in the family. Subsequently, these events directly or indirectly affect the self-esteem and the self-image of adolescents during the period of adolescence. This research starts with the assumption that stressful life events predicted anxiety during the period of adolescence. Another assumption, in this research, is that females have higher level of anxiety compared with males. This study was conducted on a sample of 160 participants ( 80 girls and 80 boys) students in the fourth year of secondary school. The instruments used in the research include: scale of stressful life events for children and adolescents - Stress-D, and the Scale for anxiety for children and adolescents - SCAD-62. The results showed that stressful life events were significantly associated with anxiety symptoms $(\mathrm{r}=.962, \mathrm{p}<.01)$. Also, the symptoms of anxiety are closely associated with medical $(\mathrm{F}, 24,135=.871, \mathrm{p}<.05)$ and family stressful events $(\mathrm{F}, 24,135=2.017, \mathrm{p}<.05)$. There were significant relationship between medical stressful life events and gender $(\mathrm{p}=.045)$, and social stressful life events and gender $(p=.001)$. On the other hand, there was a negative correlation between academic stressful life events and gender $(p=.944)$, and
\end{abstract}


family stressful life events and gender $(\mathrm{p}=.564)$. In conclusion, the results of the study show that females have higher level of anxiety compared with males $(\mathrm{r}=.985, \mathrm{p}<.01)$. The results show that there is a significant relationship between specific types of stressful life events, including those related to physical health and family which discord the anxiety during the period of adolescence.

Keywords: Stress, Stressful Life Events, Anxiety, Gender, Adolescence

\section{Introduction}

It is well known that adolescence stage has been conceptualized as a transitional period. Thus, this period begins with the onset of puberty and ends with the acceptance of the rules and responsibilities of adulthood. Of all life-stages, except childhood, adolescence is mostly considered to be a rapid and very intensive process of transition (Achenbach \& McConaughy, 1997). This is to be seen in the domain of biological development where the changes are physically and externally manifested. Furthermore, it is also seen in the progression of both cognitive and psychosocial maturity from that of childhood to a fully grown adult.

Although the adolescence period is characterized as the happiest phase of life, stress, depression, and anxiety are common problems that marks this stage of life. However, several scientific studies basically focus on determining the prevalence of adolescent stress and anxiety in different cross-cultural backgrounds. These studies confirm that the risky behaviors of adolescents are universal and are crucially governed by their experience to stress, anxiety, depression, and other social factors (Carr, 1999).

Many young persons are seriously affected by their experience of stress, depression, and anxiety. However, they may rely on various negative or positive behaviors while dealing with their problems. Stress features the feeling of anxiety, frustration, sadness, and hopelessness (Goodwin et al., 2004; Byrne \& Mazanov, 2002).

Consequently, it is known that stressful life events are commonly studied risk and environmental factors in the development of psychopathology in childhood and adolescents. The most common causes of stressful life events include break up with partners, conflicts between parents, change in the financial status of parents, death or serious illness in the family, educational pressures, and many others. Sometimes, these factors might be the result of everyday difficulties from the environment. Thus, it also includes the expectations or desires of the adolescent that has not been met. However, when faced with the stressors, the stress process and the impact from stress varies individually and leads to different health outcomes. 
This depends on individual and environmental vulnerabilities and resources, as well as the ability to cope effectively with the stressors.

Some studies reported that the total number of stressful life event during adolescence, predict various symptoms of anxiety (Perkins, 1982; Wiles et al., 2008). These researchers reported that stressful life events are significantly higher in youths with anxiety. Hence, they have suggested that certain types of events may be specific for each. The analysis of specific events showed that events consisting of changes in social relationships appeared to be specific for anxiety (Larson et al., 2002). In this same study, authors have reported that stressful life events in adolescent population characterized by loss (e.g., death), exit events (e.g., parental divorce, conflict between parents), or the ending of important love relationships appears to be more specific for anxiety symptoms.

\section{Study Objectives}

The main objective of the present study is to examine the role of stressful life events as a risk factor for the development of increased symptoms of anxiety among adolescents. In addition, it also aims to evaluate whether certain types of stressful life events are related to health, family, peers, or school problems.

\section{Methods}

\section{Participants}

The sample of students for the study was randomly selected. However, their participation in this study was voluntary. The study included 160 students (80 boys and 80 girls) from the fourth year of the secondary schools in Skopje. The mean age of the students were calculated as 17.50 (SD=6.75) years.

\section{Data Collection Tools}

Based on the scope of the study, Personal Information Form constructed by researchers, Scale of Stressful Life Events for Children and Adolescents, and the Scale for Anxiety for Children and Adolescents were used among the students.

Personal Information Form: This form includes the gender and age of the participants.

Scale of Stressful Life Events for Children and Adolescents (Stress-D): The scale developed by Vulić \& Prtorič (2002) was used on the participants. This scale showed good psychometric properties and high coefficients of internal consistency $(\alpha=0.867)$. The scale consists of 44 items which describe the academic, social, family, and medical stressful events. Each 44 stressful events correspond to the questions about his/her experience 
on the event. This assessment was carried out on a scale of 1 to 5 . Participants were asked to indicate which events they had experienced stress in the prior 6 months.

Scale for Anxiety for Children and Adolescents (SCAD-62): This scale, developed by Vulić \& Prtorič (2004), was used to measure the general anxiety level. The scale which aims to determine the level of anxiety in students is composed of 62 items. It is a two-point likert type scale where the higher scores indicate greater manifestation of anxiety. Each item presents a symptom of anxiety. Also, participants indicate how true each item is for them. However, the reliability of this scale in the normative sample of students was given as $\alpha=0.823$.

\section{Data Procedure and Data Analysis}

Data collection tools were administered by the researchers during the winter semester of the 2015-2016 academic sessions. The instruments were applied to the students in classrooms. It was set by obtaining permission from the instructors. The period for answering the scale lasted for 50 minutes. The data was analyzed using SPSS (Statistical Pacakge for Social Sciences) version 17 for Windows program. Correlation analysis (Pearson Correlation, t-test and one-way ANOVA) were employed to understand the relationships between stressful life events and the anxiety of the participants. In this study, the significance levels were accepted as .01 or .05.

\section{Results}

In this study, we observed that all participants had higher scores of stress and anxiety symptoms. As shown in Table 1, the mean Stress-D score for participants was 165.21 points, while the mean SCAD-62 score was 13.00 points. Therefore, the results show that stressful life events were significantly associated with anxiety $(r=.962, \mathrm{p}<.01)$.

Table 1. Correlations, means, and SD of stressful life events and anxiety

\begin{tabular}{|c|c|c|c|c|c|c|}
\hline & $\mathrm{N}$ & Minimum & Maximum & Mean & $\begin{array}{c}\text { Std. } \\
\text { Deviation }\end{array}$ & $\begin{array}{c}\text { Pearson } \\
\text { Correlation }\end{array}$ \\
\hline Stress-D & 160 & 54.00 & 220.00 & 165.21 & 42.30 & 1 \\
\hline SCAD-62 & 160 & 2.00 & 27.00 & 13.00 & 4.86 & $.962 * *$ \\
\hline
\end{tabular}

As can be seen from Table 2, symptoms of anxiety are significantly associated only with the medical $(\mathrm{F}, 24,135=.871, \mathrm{p}<.05)$ and family stressful events $(F, 24,135=2.017, \mathrm{p}<.05)$. Therefore, the results show that stressful life events, especially the medical problems and problems in the family, predicted anxiety during the period of adolescence. 
Table 2. Summary of One way ANOVA between anxiety and the type of stressful life events among the students

\begin{tabular}{|c|c|c|c|c|c|c|}
\hline & Source of Variation & $\begin{array}{c}\text { Sum of } \\
\text { Squares }\end{array}$ & df & $\begin{array}{c}\text { Mean } \\
\text { Square }\end{array}$ & F & Sig. \\
\hline Medical & Between Groups & 1169.93 & 24 & 48.74 & .871 & $\mathrm{P}<.05$ \\
\hline & Within Groups & 7555.04 & 135 & 55.96 & & \\
\hline & Total & 8724.97 & 159 & & & \\
\hline Academic & Between Groups & 2977.80 & 24 & 124.07 & 1.174 & $\mathrm{P}>.05$ \\
\hline & Within Groups & 14264.93 & 135 & 105.66 & & \\
\hline & Total & 17242.74 & 159 & & & \\
\hline Social & Between Groups & 2614.19 & 24 & 108.92 & 1.016 & $\mathrm{P}>.05$ \\
\hline & Within Groups & 14478.20 & 135 & 107.24 & & \\
\hline Family & Total & 17092.40 & 159 & & & \\
\hline & Between Groups & 7989.50 & 24 & 332.89 & 2.017 & $\mathrm{P}<.05$ \\
\hline & Within Groups & 44203.30 & 135 & 327.43 & & \\
\hline & Total & 52192.84 & 159 & & & \\
\hline
\end{tabular}

However, the results of the SCAD-62 scores were portrayed in Table 3. In Table 3, a wide range was seen in SCAD-62 scores of the students. The mean SCAD-62 score among females was 13.90 points, while the mean SCAD-62 score among males was 11.91 points. Also, the girls showed higher physiological and emotional anxiety than the boys. Difference between the two study groups was significant at the level of $\mathrm{p}<.05$.

Table 3 . The level of the SCAD-62 scores among the responders

\begin{tabular}{|c|c|c|c|c|c|c|}
\hline SCAD-62 & $\mathrm{N}$ & Minimum & Maximum & Mean & $\begin{array}{c}\text { Std. } \\
\text { Deviation }\end{array}$ & $\begin{array}{c}\text { Pearson } \\
\text { Correlation }\end{array}$ \\
\hline Boys & 80 & 2.00 & 23.00 & 11.91 & 4.54 & 1 \\
\hline Girls & 80 & 2.00 & 27.00 & 13.90 & 4.23 & $.985^{* *}$ \\
\hline
\end{tabular}

At the same time from the Table 4, we observed that stressful life events was strongly correlated with the gender of the subjects $(\mathrm{r}=.990, \mathrm{p}<.01)$.

Table 4. The level of the Stress-D scores among the responders

\begin{tabular}{|c|c|c|c|c|c|c|}
\hline Stress-D & $\mathrm{N}$ & Minimum & Maximum & Mean & $\begin{array}{c}\text { Std. } \\
\text { Deviation }\end{array}$ & $\begin{array}{c}\text { Pearson } \\
\text { Correlation }\end{array}$ \\
\hline Boys & 80 & 48.00 & 220.00 & 149.40 & 45.51 & 1 \\
\hline Girls & 80 & 54.00 & 220.00 & 156.46 & 48.00 & $.990 * *$ \\
\hline
\end{tabular}

As shown in Table 5, there was positive correlation between medical subscale and gender $(\mathrm{p}=.045)$ and social subscale and gender $(\mathrm{p}=.001)$. 
Table 5. Correlation between the type of stressful life events and gender

\begin{tabular}{|c|c|c|c|c|c|c|}
\hline Variables & Gender & Mean & $\mathrm{N}$ & Std. Deviation & $\mathrm{T}$ & $\mathrm{P}$ \\
\hline \multirow{2}{*}{ Medical } & Boys & 27.41 & 80 & 8.95 & -2.024 & 0.045 \\
\cline { 2 - 6 } & Girls & 29.27 & 80 & 8.58 & & \\
\hline \multirow{2}{*}{ Academic } & Boys & 28.60 & 80 & 10.40 & -0.07 & 0.944 \\
\cline { 2 - 6 } & Girls & 28.68 & 80 & 10.99 & & \\
\hline \multirow{2}{*}{ Family } & Boys & 31.21 & 80 & 11.38 & -3.4 & 0.001 \\
\cline { 2 - 5 } & Girls & 35.15 & 80 & 11.20 & & \\
\cline { 2 - 5 } & Boys & 62.03 & 80 & 19.29 & -0.573 & 0.564 \\
\cline { 2 - 5 } & Girls & 63.30 & 80 & 20.49 & & \\
\hline
\end{tabular}

\section{Discussion}

Adolescents, in the process of growing up, frequently encounter a range of life experiences or events that may result to changes in their lives. They experience the birth of their siblings. Furthermore, they gain admission into school, oftentimes, and they change from one school to another. In our mobile society, these school changes are often associated with a change in resistance. Thus, this may in turn be correlated with a host of other changes that require additional coping efforts. Parental separation and divorce, serious illness or injury to family members, deaths in the family and illness experienced by the children themselves, are among other life events that affect the lives of adolescents (Burnett et al., 2007). Although these young people vary to the extent in which they experience significant life changes, such events are a potential source of stress to which all adolescents are exposed to a greater or a lesser degree of it.

In the current study, we sought to address several gaps in the literature on anxiety symptoms among adolescents. The first goal is to examine stressful life events as a contributor to increased anxiety symptoms in adolescents. Therefore, the findings that stressful life events were significantly more frequent among adolescents are consistent with studies that reported that stressful life events are correlated with anxiety (Goodwin et al., 2004). Also, some researchers suggest that the experience of stressful life events increases certain types of self-focused repetitive thought, such as rumination (Robinson \& Alloy, 2008; Chop Rite \& Barlow, 1998). The other suggests that anxiety-related cognitions are the consequences of anxiety symptoms. As a result, it might lead to the development of negative beliefs about the consequence of anxiety symptoms (Watkins, 2008).

The types of stressors experienced in adolescence can be divided into three categories. These categories are normative events, non-normative events, and daily hassles (Swearingen \& Cohen, 1985). However, the focus of this paper is majorly on normative events and daily hassles. Normative events refer to events that are experienced by most adolescents. Examples of these events includes internal and external changes related to pubertal 
development, psychosocial changes related to school, family, peers, and academic demands.

The results of our study show that total own stress as well as domain specific stressors in interpersonal contexts (home) and in the health environment, are important stressors in relation to adolescents psychological functioning and in the experience of subjective health complaints. Thus, our findings suggest that intrapersonal mechanism links stress to anxiety symptoms (Barlow, 2005). At the same time, girls appear to be more vulnerable to the negative psychological effect of stress than boys. Some researchers said that the effect of cumulative and simultaneous stressors can threaten the well-being and healthy development of girls and boys during their period of adolescence (Meknes et al., 2010; Rudolph, 2002).

\section{Conclusion}

Adolescence is a developmental period characterized by multiple changes in virtually every aspect of an individual's life, calling for new psychological adaptations. Exposure to different stressors caused by these changes represents a central and normal part of the processes of growth and development during adolescents.

In conclusion, the current study identified stressful life events as a factor related to the development of increasing anxiety among adolescents. The thesis shows that both the total sum of stress and the domain specific stress, especially in interpersonal contexts, are related to more emotional problems. The present thesis shows an investigation of the role and nature of adolescent stressors. It also shows the association between stress and different health outcomes, such as anxiety. Gender differences on stress and anxiety were also considered. However, girls reported higher levels of stress and more negative health problems than boys. So, the transition into adolescence seems to be the starting point for an increase in psychological problems like anxiety, psychosomatic symptoms, or depression.

Some limitations of this study should be kept in mind by examining the results. First, the sample was restricted to adolescents from only secondary schools in Skopje. Thus, the results may not be general to all Macedonian young people. Further research should be carried out with groups of undergraduate students from several towns in Macedonia. Also, further studies should be conducted with different demographic variables such as ethnicity, family size, socioeconomic status, and different personality traits.

\section{Recommendations}

In view of the present findings, these results have potentially important treatment implications. Thus, preventive interventions that focus on anxiety 
may help to reduce stress-related psychological and psychiatric morbidity in adolescents.

\section{Acknowledgements}

The authors would like to express their sincere gratitude to all students who participated in this study.

\section{References:}

Achenbach \& McConaughy (1997). Empirically based assessment of child and adolescent psychopathology. London: SAGE Publications.

Barlow (2005). Anxiety and its disorders. New York: Guilford Press.

Burnett et al. (2007). Family life stress and insomnia symptoms in a prospective evaluation of young adults. Journal of Family Psychology, 21:58-66.

Byrne \& Mazanov (2002). Sources of stress in Australian adolescents: factor structure and stability over time. Stress and Health, 18:185-192.

Carr (1999). The Handbook of Child and Adolescent Clinical Psychology. London, New York: Rout ledge.

Chop Rite \& Barlow (1998). The development of anxiety: The role of control in the early development. Psychological Bulletin, 124:3-21.

Grant et al. (2003). Stressors and child and adolescent psychopathology: Moving from markers to mechanisms of risk. Psychological Bulletin, 129:447-466.

Goodwin et al. (2004). Early anxious/withdrawn behaviors predict lateral internalizing disorders. Journal of Child Psychology and Psychiatry, 45:874883.

Goodyear \& Kelvin (1985). Recent undesirable life events and psychiatric disorder in childhood and adolescence. British Journal of Psychiatry, 147:517-523.

Larson et al. (2002). Continuity, stability and change in daily experience across adolescence. Child Development, 29:130-140.

Meknes et al. (2010). The association between stress and emotional states in adolescents: the role of gender and self-esteem. Personality and Individual Differences, 49:430-435.

Perkins (1982). The assessment of stress using life events scale. In: Handbook of Stress: Theoretical and Clinical Aspects. NY, London: The Free Press.

Rudolph (2002). Gender differences in emotional responses to interpersonal stress during adolescence. Journal of Adolescent Health, 30:3-13.

Robinson \& Alloy (2008). Negative cognitive styles and stress-reactive rumination interact to predict depression: A prospective study. Cognitive Therapy and Research, 27:275-291. 
Swearingen \& Cohen (1985). Life events and psychological distress: A prospective study of young adolescents. Dev Psychology, 21:1045-1054. Vulić \& Prtorič (2004). Priručnik za skala strahova i anksioznosti za djecu i adolescente SCAD-62. Jastrebarsko: Naklada Slap.

Vulić \& Prtorič (2002). Prikaz skale stresnih nastana za djecu i adolescente STRES-D. Jastrebarsko: Naklada Slap.

Watkins (2008). Constructive and unconstructive repetitive thought. Psychological Bulletin, 111:471-477.

Wiles et al. (2008). Physical activity and emotional problems among adolescents: a longitudinal study. Social Psychiatry and Psychiatric Epidemiology, 43:765-772. 